\title{
EXPERIMENTAL EFFECT OF FEEDING ON RICINUS COMMUNIS AND BOUGAINVILLEA GLABRA ON THE DEVELOPMENT OF THE SAND FLY PHLEBOTOMUS PAPATASI (DIPTERA: PSYCHODIDAE) FROM EGYPT
}

By

\author{
RANIA M. KALDAS ${ }^{1}$, AZZA S. EL SHAFEY ${ }^{2}$, MAGDI G. SHEHATA ${ }^{3}$, \\ ABDALLAH M. SAMY ${ }^{3,4}$ and JEFFREY T. VILLINSKI ${ }^{1}$
}

Vector Biology Research Program, U.S. Naval Medical Research Unit No. 3 (NAMRU-3), Cairo ${ }^{1}$, Departments of Botany ${ }^{2}$ and Entomology ${ }^{3}$, Faculty of Science, Ain Shams University, Cairo, Egypt and Biodiversity Institute, and the Department of Ecology and Evolutionary Biology ${ }^{4}$, University of Kansas, Lawrence, KS, USA (Correspondence: Ms. Rania M. Kaldas, e-mail: rania.kaldas.eg@med.navy.mil)

\begin{abstract}
Plants are promising sources of agents useful for the control of vectors of human diseases including leishmaniasis. The effect of Ricinus communis (Euphorbiaceae) and Bougainvillea glabra (Nyctaginaceae), on transmission of leishmaniasis was investigated using them as diets for Phlebotomus papatasi to monitor their effect on life-history traits. $P$. papatasi were allowed to feed separately on both plants then offered a blood-meal. Fed-females were observed daily for egg-laying and subsequent developmental stages. $P$. papatasi was able to feed on B. glabra $(29.41 \%$ females and $46.30 \%$ males) and $R$. communis $(5.80 \%$ females and $10.43 \%$ males). $34.28 \%$ of females died within $24-48$ hours post-feeding on $R$. communis, whereas, it was $16.5 \%$ in females fed on B. glabra. Overall fecundity of surviving females was reduced compared to controls, reared on standard laboratory diet; however there was no effect on the sex ratio of progeny. Female $P$. papatasi in the control group had significantly longer life span compared to plant-fed group. Feeding on these plants not only decreased sand fly survival rates but incurred negative effects on fecundity. Findings indicate that planting high densities of $R$. communis and B. glabra in sand flies-endemic areas will reduce population sizes and reduce the risk of Leishmania major infections.
\end{abstract}

Keywords: Phlebotomus papatasi - Ricinus communis - Bougainvillea glabra - Egypt

\section{Introduction}

Phlebotomus papatasi (Scopoli) has a broad geographical distribution, and is the principal vector of Leishmania major throughout the Mediterranean basin, Middle East, Central Asia, and North Africa (Feliciangeli, 2004). Sand fly distribution within that range is determined by local environmental factors such as frequency of precipitation, land surface temperature, Normalized Difference Vegetation Index, physical barriers, habitat availability and the distribution and abundance of the sylvan reservoirs (Peterson and Shaw, 2003). P. papatasi was first reported in Egypt in 1917, and has been shown by several studies to be the predominant species in the country (Willcocks, 1917; Hoel et al, 2007). Cutaneous lesions resulting from infection by $L$. major typically self-heal within several months in immune-competent patients and injection with intra-lesional antimonals are often a prescribed treatment of the parasites (Porrozzi et al, 2004; Alborzi et al, 2006).

Plants have always been an important source of active compounds against insects and they have developed several compounds that are still used in modern day insecticides. 
Insect evolution is characterized by rapid adaptation with selective pressures exerted by environment and is closely related to the evolution of flowering plants. The adaptations include feeding on plant sap (Moran et al, 2005; Janson et al, 2008). Studies have shown that some phytochemicals have a toxic effect on insect adults and larvae by interfering in their growth, development and/or reproduction, or by producing attractive or repellent scents (Amóra et al, 2009). The Neem Azadirachta indica oil had a repellency activity against $P$. papatasi when used for three days at concentrations of $1 \%$ and $2 \%$ (Srinivasan and Kalyanasundaram, 2001) that was reported later to be due to the active ingredient azadirachtin, that was shown to kill sand fly larvae in laboratory experiments (Andrade-Coelho et al, 2009).

Other plant extracts are highly toxic to the sand fly Lutzomyia longipalpis, such as dried leaf extracts of Antonia ovata (Loganiaceae) and Derris amazonica (Papillionaceae) killing $80 \%$ and $100 \%$ of females, respectively, $72 \mathrm{~h}$ after exposure (Luitgards-Moura et al,2002). The repellency effect of the garlic (Allium sativum) oil was also evaluated on $P$. papatasi females, at $1 \%$, the oil had a repellency effect of 97\% (Valerio and Maroli, 2005). Some plants, such as Solanum jasminoides, Ricinus communis, Bougainvillea glabra, are toxic to adult sand flies and could therefore represent a readily available alternative to the commercial insecticides for sand fly control (Schlein et al, 2001). Certain plants (e.g.; Capparis spinosa, Ricinus communis, Bougainvillea glabra and Solanum luteum) used as sources of sugar by sand flies are toxic to L. major, and these are also able to kill sand flies (Schlein and Jacobson, 1994; Jacobson and Schlein, 1999; Schlein and Jacobson, 1999). Host plant is a key determinant of the sand fly life cycle (Schlein et al, 2001) and plants diet can also affect insect reproductive strategies, and the life history traits. Male sand flies feed mainly on plant sap as their major source of nutrients, however, females require a blood meal to support the egg development, and use the sugar meal as a source of the energy (Killick-Kendrick, 1999; Benkova and Volf, 2007). R. communis is a natural vegetation of the Egyptian fauna, while B. glabra is cultivated.

The present study investigates the effect, if any, of 1) feeding on two different plant species, $R$. communis and B. glabra and accessing resulting mortality, 2) Interference of feeding on the two plants with $P$. papatasi's survival and fecundity, and 3 ) Monitoring subsequent changes in the sand fly's life cycle. This study was conducted as an initial step to highlight the use of natural sources as plants to control diseases-causing vectors in endemic populations.

\section{Materials and Methods}

The laboratory colony was initiated in 1989 using adult wild caught sand flies from El-Arish in the North Sinai Governorate in Egypt by the U.S. Naval Medical Research Unit No. 3 (NAMRU-3); sand flies used in the current experiments were the $106^{\text {th }}$ generation from the initial colony. Rearing was done in NAMRU-3 according to standard methods of Modi and Tesh (1983) with minor changes, at a stable monitored temperature of $27 \pm 1{ }^{\circ} \mathrm{C}, 70-80 \%$ relative humidity (RH), and a 12:12 (Light: Dark) photoperiod. Syrian golden hamsters (Mesocricetus auratus)*, with an average weight of $160 \pm 40 \mathrm{~g}$, were used as the bloodmeal source for colony rearing. Prior to sand flies feeding process, hamsters were previously anaesthetized by the intra-peritoneal (IP) injection of Ketaset ${ }^{\circledR}(0.1 \mathrm{ml} / 100 \mathrm{~g}$ Body Weight, Fort Dodge $\AA$, USA). After the blood meal, fed females were separated to a new cage, given a $24 \mathrm{~h}$ recovery period and then aspirated individually into a $50 \mathrm{ml}$ polymethyl-pentene rearing vials at the controlled $(70-80 \%)$ relative humidity to oviposit. 
Plant seeds originating from South of Egypt were brought to the Botanical Garden of Ain Shams University, where they had been grown without fertilizers, pesticides or other chemical treatments. Branches of $R$. communis and B. glabra were readily available for feeding processes. Freshlyharvest branches were cut under water and transferred to the laboratory within $1 \mathrm{~h}$. To track feeding by sand flies, branches were first suffused with blue food dye (Kamina, Egypt) by placing their stems in $200 \mathrm{ml}$ Erlenmeyer flasks filled with $1 \%$ dye and $0.127 \mathrm{M}$ sucrose solution, then left for 24-48 $\mathrm{h}$ as described by Schlein and Jacobson (2008).

For each sand fly feeding trial of the seven trials done for this study, 100-150 newly emerged $P$. papatasi (1-3 days old) adults were placed in cages containing blue dyedbranches of either $R$. communis or B. glabra for 24-48 h. Sand flies used in the feeding trials, were a total of 2130 flies, of which, 996 flies were allowed to feed on $R$. communis, 594 flies were allowed to feed on B. glabra and 540 flies were used as controls and were fed $30 \%$ sucrose solution. Flies were monitored daily to determine if feeding had occurred; feeding was detected by the presence of blue food-dye in the guts of fed P. papatasi (Fig. 1). For control experiment, female and male adults of the same age were fed on $30 \%$ sucrose solution and received a blood meal at the same time with the experimental groups. Plant-feeding trials covered a period of 13 months of the study, during which a feeding trial was repeated every 1.5 month, which resemble a sand fly's complete life cycle.

To identify which sand flies had fed on the plants; individuals were aspirated from the feeding cages, anesthetized using $\mathrm{CO}_{2}$ and observed on a cold plate to detect the presence of the blue marker dye (Fig. 1). Successful feeders were released into new cages, starved for 2-4 $\mathrm{h}$ then allowed to feed on Syrian golden hamster as the blood meal source using the same blood feeding procedure and precautions as mentioned above. Each blood-fed female sand fly was separated in rearing vial, where it was observed daily for oviposition. Each rearing vial was observed daily to measure lifehistory parameters for each stage of the life cycle, starting with counting the numbers of oviposited eggs, hatched larvae, developed pupae and finally adults. The timing of developmental stages was also recorded. Flies were kept under controlled insectary conditions throughout the whole study. Standard batches of larval food, prepared as described by Modi and Tesh (1983) were used to maintain the survival of hatched eggs.

Statistical analysis: The statistical analysis of the data was performed using the one-way ANOVA, by GraphPad Prism version 5.00 for Windows (GraphPad Software, San Diego California USA, www.graphpad. com). Normal (Z-test) for proportions was applied to access the influence of feeding on $R$. communis or B. glabra and the rate of mortality in the flies. Results were expressed as mean $\pm \mathrm{SE}$ and considering $95 \%$ as significance level between averages. "Post Hoc" Tukey's HSD test for the multiple comparisons was utilized to ascertain the extent of the difference made by different plant meal sources on each variable of the life-history parameters of the sand flies. The control group was compared against both treatments of $R$. communis and B. glabra.

\section{Results}

A total of 2130 flies (1279 females and 851 males) were allowed to feed on $R$. communis, B. glabra or $30 \%$ sucrose solution. A total of 996 flies (603 females and 393 males) were allowed to feed on $R$. communis, of these, 35 females $(5.80 \%)$ and $41(10.43 \%)$ males were able to feed. whereas, a total of 594 flies (391 females and 203 males) were allowed to feed on $B$. glabra, of these, 115 females (29.41\%), and 94 males $(46.30 \%)$ were able to feed. For the 540 flies (285 females and 255 males) that were allowed to feed on $30 \%$ sucrose solution, 265 females (93\%) and 228 males 
$(89.41 \%)$ were able to feed (Table 1). Sand fly feeding rates varied significantly among the three sources $(R$. communis, B. glabra and control; $\mathrm{F}=5.26, \mathrm{df}=2, \mathrm{P}<0.05)$. The present findings showed that there was a noticeable difference in the feeding of $P$. papatasi sand flies on $B$. glabra and $R$. communis, with $B$. glabra being the highest, either in female or male sand flies. Some sand flies died 24-48 hours post-feeding on the plants, notably after feeding on $R$. communis where the mortality rate was $34.28 \%$ (12 out of 35 ) for females and $14.63 \%$ (6 out of 41 ) for males (Fig. 2). Mortality rates were $16.52 \%$ (19 out of 115 ), and $24.46 \%$ (23 out of 94 ) for females and males, respectively after feeding on $B$. glabra. Mortality rates did not exceed $1 \%$ for males $(1 / 228,0.43 \%)$ or females $(1 / 265$, $0.37 \%$ ) fed on the control solution. The mortality rates in either female or male $P$. papatasi were highly significant $(\mathrm{p}<0.005)$ after feeding on $R$. communis and B. glabra when compared to morality rates in sand flies due to feeding on the $30 \%$ sucrose solution, by the normal test (Z-test) for proportions.

Phlebotomus papatasi females fed on sugar solution and blood laid significantly more eggs (43.49 \pm 3.704$)$ than those fed on $R$. communis or B. glabra (Table 2) which retained fewer eggs after oviposition. Few females fed on $R$. communis survived till the oviposition (11 out of 35). These females laid a mean \pm SE of $(9.34 \pm 3.027)$ eggs. A similar decrease in fecundity occurred in the sand fly $P$. papatasi fed on B. glabra. The females fed on Bougainvillea laid an average number \pm SE of eggs of $(29.80 \pm 2.903)$ which is more than the eggs laid by the female fed on Ricinus, however, eggs laid in both cases were fewer than those laid by females which received a normal diet regimen (Sugar 30\% and blood). Post hoc (Tukey HSD) analysis showed complete significant difference $(\mathrm{P}<0.05)$ in the mean number of eggs laid in all plant treatment groups and also in the control.
Sand flies feeding on $R$. communis or $B$. glabra produced fewer larvae compared to control groups $(\mathrm{P}<0.005$, Table 2$)$. The number of the larvae was reduced to a mean of $(6.34 \pm 2.225)$ and $(20.71 \pm 2.606)$ larvae for $R$. communis and B. glabra, respectively, whereas, the mean number of larvae in control females was $(29.43 \pm 3.649)$ (Table 2). Post hoc analysis showed significant difference $(\mathrm{P}<0.05)$ in mean number of hatched eggs in $R$. communis against $B$. glabra and control groups, thus producing fewer fragment numbers of larvae. Similar observations were reported for the larvae pupated into the next pupal stage; Fewer numbers of pupae were developed for the females fed on both exotic plants, with mean number of pupae of $(5.57 \pm 2.000)$ and $(16.43 \pm 2.118)$ for the $R$. communis and $B$. glabra, respectively, whereas, a higher number of pupae populations were developed in the control group with a mean of $\quad(25.23 \pm 3.471) \quad(\mathrm{P}<0.005)$. Post hoc analysis showed a significant reduction in the number of larvae, and pupae that revealed the effect of exotic plant feeding by the mother on the progeny's development to larval and pupal stages. The significant difference $(\mathrm{P}<0.05)$ in mean number of pupae was detected in $R$. communis against $B$. glabra and control group.

There was a difference in the number of males, and females emerging from pupae developed from females that received the $R$. communis $(4.91 \pm 1.762)$ or $B$. glabra $(14.29 \pm 1.828)$ treatments compared with the control $(23.11 \pm 3.229)$. The number of males and females was highly reduced particularly upon feeding on $R$. communis treatment. Post hoc analysis showed significant difference $(\mathrm{P}<0.05)$ in adult emergence in $R$. communis against B. glabra and control groups. There was no difference in the emerging adult sex ratio (Female: Male) in each treatment and was found close to 1: 1 ratio in all treatments.

The duration of the life cycle in $P$. papatasi females fed on sugar solution and 
blood was significantly longer than the life communis or B. glabra (Table 3). In females cycles of those fed on the plants; $R$.

Table 1: Total number and percentage of feeding of P. papatasi sand flies on Ricinus communis, Bougainvillea glabra, and $30 \%$ sucrose solution (control)

\begin{tabular}{|c|c|c|c|c|c|}
\hline \multirow{2}{*}{ Type of meal } & \multicolumn{3}{|c|}{ Total number of flies per Experiment } & \multirow{2}{*}{$\begin{array}{c}\text { Fed females } \\
(\%)\end{array}$} & \multirow{2}{*}{$\begin{array}{c}\text { Fed males } \\
(\%)\end{array}$} \\
\hline & Female & Male & Total & & \\
\hline R. communis & 603 & 393 & 996 & $35(5.8)$ & $41(10.43)$ \\
\hline B. glabra & 391 & 203 & 594 & $115(29.41)$ & $94(46.3)$ \\
\hline Control (30\% sucrose solution) & 285 & 255 & 540 & $265(93)$ & $228(89.41)$ \\
\hline
\end{tabular}

Table 2: Life-history consequences of female $P$. papatasi sand fly after feeding on $R$. communis, B. glabra or $30 \%$ sucrose solution

\begin{tabular}{|l|l|l|l|l|l|}
\hline $\begin{array}{l}\text { Life-history stage/ } \\
\text { Type of meal }\end{array}$ & $\begin{array}{l}\text { Ricinus communis } \\
\text { Mean number } \pm \text { SE }\end{array}$ & $\begin{array}{l}\text { Bougainvillea glabra } \\
\text { Mean number } \pm \text { SE }\end{array}$ & $\begin{array}{l}\text { 30\% sucrose soln. } \\
\text { Mean number } \pm \text { SE }\end{array}$ & $\begin{array}{l}\text { F- } \\
\text { value }\end{array}$ & $\begin{array}{l}\text { P- } \\
\text { Value }\end{array}$ \\
\hline No. of laid eggs & $9.34 \pm 3.027$ & $29.80 \pm 2.903$ & $43.49 \pm 3.704$ & 28.291 & $<0.005$ \\
\hline No. of larvae & $6.34 \pm 2.225$ & $20.71 \pm 2.606$ & $29.43 \pm 3.649$ & 16.186 & $<0.005$ \\
\hline No. of pupae & $5.57 \pm 2.000$ & $16.43 \pm 2.118$ & $25.23 \pm 3.471$ & 14.164 & $<0.005$ \\
\hline No. of adults & $4.91 \pm 1.762$ & $14.29 \pm 1.828$ & $23.11 \pm 3.229$ & 14.735 & $<0.005$ \\
\hline No. of females & $2.91 \pm 1.083$ & $6.91 \pm 0.945$ & $11.83 \pm 1.741$ & 11.740 & $<0.005$ \\
\hline No. of males & $2.00 \pm 0.691$ & $7.37 \pm 1.019$ & $11.29 \pm 1.557$ & 16.553 & $<0.005$ \\
\hline
\end{tabular}

\section{$\mathrm{F}$ : ratios}

Table 3: Effect of feeding on R. communis, B. glabra or 30\% sucrose solution on pre-oviposition, oviposition, larval, pupal, life cycle, and egg incubation periods

\begin{tabular}{|c|c|c|c|c|c|}
\hline $\begin{array}{c}\text { Duration/Type of } \\
\text { meal }\end{array}$ & $\begin{array}{l}\text { Ricinus communis } \\
\text { Mean duration } \pm \mathrm{SE}\end{array}$ & $\begin{array}{l}\text { Bougainvillea glabra } \\
\text { Mean duration } \pm \mathrm{SE}\end{array}$ & $\begin{array}{l}30 \% \text { sucrose soln. } \\
\text { Mean duration } \pm \mathrm{SE}\end{array}$ & $\begin{array}{c}\text { F- } \\
\text { Value }\end{array}$ & $\begin{array}{c}\text { P- } \\
\text { Value }\end{array}$ \\
\hline $\begin{array}{l}\text { Pre-oviposition } \\
\text { duration }\end{array}$ & $2.89 \pm 0.784$ & $8.97 \pm 0.637$ & $10.20 \pm 0.122$ & 44.449 & $\begin{array}{c}< \\
0.005\end{array}$ \\
\hline Oviposition duration & $0.43 \pm 0.131$ & $1.11 \pm 0.114$ & $1.51 \pm 0.103$ & 22.03 & $\begin{array}{c}< \\
0.005\end{array}$ \\
\hline Larval duration & $4.83 \pm 1.412$ & $15.09 \pm 1.086$ & $17.46 \pm 0.898$ & 33.958 & $\begin{array}{c}< \\
0.005\end{array}$ \\
\hline Pupal duration & $2.74 \pm 0.804$ & $6.89 \pm 0.500$ & $8.86 \pm 0.496$ & 25.593 & $\begin{array}{c}< \\
0.005\end{array}$ \\
\hline Life Cycle & $7.57 \pm 2.209$ & $22.03 \pm 1.561$ & $26.40 \pm 1.300$ & 32.345 & $\begin{array}{c}< \\
0.005\end{array}$ \\
\hline $\begin{array}{l}\text { Egg incubation } \\
\text { period }\end{array}$ & $1.77 \pm 0.522$ & $4.97 \pm 0.359$ & $5.74 \pm 0.305$ & 26.932 & $\begin{array}{c}< \\
0.005\end{array}$ \\
\hline
\end{tabular}

F: ratios 
fed on $R$. communis, the pre-oviposition time was $(2.89 \pm 0.784)$ days, and the oviposition duration was $(0.43 \pm 0.131)$ days, whereas, the larval duration, and pupal duration were $(4.83 \pm 1.412)$ and (2.74 \pm 0.804$)$ days, respectively. On the other hand, females fed on B. glabra had longer pre-oviposition and oviposition time $(8.97 \pm 0.637)$ and $(1.11 \pm 0.114)$, respectively if compared with $R$. communis, also the same applies for larval and pupal durations $(15.09 \pm 1.086)$ and $(6.89 \pm 0.500)$ days, respectively. Egg incubation period was shorter in the treatment with $R$. communis (1.77 \pm 0.522$)$ than B. glabra $(4.97 \pm 0.359)$ days. Overall life cycle duration was significantly different in $R$. communis than the control treatment $(7.57 \pm 2.209)$ and $(26.40 \pm 1.300)$ days, respectively. Also, life cycle was significantly different in $B$. glabra treatment $(22.03 \pm 1.561)$ days. Post hoc analysis showed significant differences $(\mathrm{P}<0.05)$ in oviposition duration between both plant meals and the control, while it showed significant difference $(\mathrm{P}<0.05)$ in pre-oviposition duration, egg incubation period, larval duration, pupal duration and life cycle for $R$. communis against $B$. glabra and control group.

\section{Discussion}

There is not a lot of attention directed at research to assess influence of plant meals on $P$. papatasi egg production and developpment of the sand fly throughout the life cycle led to the current study which aims to understand the post-feeding effect of two control-candidate plants $R$. communis and $B$. glabra on the survival and development of $P$. papatasi, the vector for zoonotic cutaneous leishmaniasis in the Mediterranean region. To our knowledge and according to the literature reviews, no studies had examined such effect and the present results support the idea that strategically chosen plant species can be used as means of local sand fly control. R. communis and B. glabra have been proven to be attractive and of preference when they were available in the vicinity of $P$. papatasi sand flies in natural settings (Schlein and Yuval, 1987; Schlein and Jacobson, 1994), they also previously reported feeding on branches of $R$. communis by $71 \%$ of $P$. papatasi in the laboratory. In the same context, feeding on branches of $R$. communis was reported in $62.1 \%$ of $P$. papatasi and $54.2 \%$ on $B$. glabra in the field. Schlein et al, (2001) reported feeding for both $P$. papatasi sexes. The latter concluded that there was no significant difference in the overnight feeding rates between male and female flies. Our findings agreed with the previously mentioned research in the proven feeding of $P$. papatasi on both plants, however indicated that $5.80 \%$ and $29.41 \%$ of female flies of $P$. papatasi were able to feed on the $R$. communis and B. glabra, respectively. Feeding rates of males were higher than that of females $(10.43 \%$ and $46.30 \%$ for $R$. communis and B. glabra, respectively), and also showing higher feeding rates for $B$. glabra meal against $R$. communis in both sexes. Sand flies fed on either plants suffered mortality within 1-2 nights postfeeding. Mortality rates were $34.28 \%$ for females and $14.63 \%$ for males after feeding on $R$. communis, and $16.52 \%$ for females and $24.46 \%$ for males after feeding on $B$. glabra. These results agree with Schlein et al, (2001), who observed that one night feeding on branches of $R$. communis or $B$. glabra drastically shortened the life span of $P$. papatasi.

Depending on the availability of host and the type of the blood meal, there is great influence on biological parameters of the sand fly especially on the fecundity (Noguera et al, 2006). The present data demonstrated that there was an effect of feeding of flies on the two plants on such biological parameters including fecundity, number of larvae, and number of pupae produced by each female in the study. This pattern has not been previously described to monitor the influence of the plant meal on 
the sand fly, according to literature. Few females were able to survive for the oviposition post-feeding on $R$. communis or B. glabra, and these females laid significantly fewer eggs in comparison to those laid by the females fed on the $30 \%$ sucrose solution.

Hatchability, larval and pupal development of the progeny were also drastically influenced post-feeding on either plant meals, reduced number of larvae and pupae were observed following feeding on $R$. communis or $B$. glabra than on sucrose solution. Previous reports had communicated the effectiveness of aqueous extracts from leaves of $R$. communis as larvicides against $2^{\text {nd }}$ and $4^{\text {th }}$ instar larvae of four mosquito species, Culex pipiens. Aedes caspius, Culiseta longiareolata and Anopheles maculipennis (Aouinty et al, 2006). A similar situation was reported by Kumar et $a l$, (2012), where crude extracts of $R$. communis possessed significant larvicidal potential against Aedes aegypti larvae. Leaf extracts of $R$. communis were tested against Rhipicephalus microplus ticks. The extract significantly affected the mortality rate of ticks in a dose-dependent manner and the survivors laid fewer eggs. When they tested the efficacy of solvent guided fractions of the extract, among the four fractions, mortality was only recorded in ticks treated with n-butanol and hexane guided fractions but not with the chloroform and water soluble fractions. The highest oviposition inhibition was observed in the chloroform guided fraction. In addition, the extract showed significant efficacy against diazinon, deltamethrin and multi-acaricide resistant ticks (Ghosh et al, 2013).

Adult emergence of males and females was highly reduced, particularly of $P$. papatasi fed on $R$. communis. Females fed on B. glabra had longer pre-oviposition, larval and pupal durations if compared with $R$. communis. Similarly, the eggs incubation period was longer after feeding on $B$. glabra compared to $R$. communis. The detailed recording of each developmental stage of $P$. papatasi from the Sinai region of Egypt based on plant intake has not been previously well described. The prior observational studies of adult sand flies from the vicinity of plants had only suggested a possible control relationship between sand flies and plants. The effectiveness of the two tested plants in reducing mean numbers of immature stages and progeny's adult emergence of $P$. papatasi is likely due to the presence of secondary metabolites.

Phytochemical analysis of methanolic extractions of $R$. communis leaves has reported a variety of tannins, saponins, flavonoids, alkaloids and terpenoids (Rondon et al, 2011). Finger printing profile of $R$. communis leaf extract showed the presence of quercetin, gallic acid, flavone and kaempferol (Ghosh et al, 2013). Quercetin, a flavonoid isolated from leaves of $R$. communis was reported to interfere with the iron metabolism in L. donovani, and was found to reduce splenic burden in infected hamsters by $75-95 \%$ (Sen et al, 2008). Fractions of $R$. communis leaf extracts confirmed the presence of saponins, which are steroid substances with various biological activities, saponins increase membrane permeability of the parasite leading to their lysis (Rondon et al, 2011).

Ethanolic extractions of $B$. glabra leaves have been reported to contain a variety of tannins, saponins, flavonoids, steroids, alkaloids, anthraquinones, glycosides, proteins, reducing sugar and starch (Joshny et $a l, 2012)$. Also, quercetin, kaempferol and isohamnetin have been detected in B. glabra extracts (Su-Xia et al, 2010). Anthraquinones, are secondary metabolites belonging to the group of quinones and are found in fractions of B. glabra leaves, were reported to inhibit the synthesis of nucleic acids and therefore inhibit the formation of proteins in bacteria (Levin et al, 1988), which was believed to be the cause of the effect on $L$. infantum promastigotes (Rondon et al, 2011). 
Controlling sand fly populations is challenging. The main reason is that the immature stages are dispersed and inaccessible as in rodent burrows. Barrier treatments with insecticides to control adult populations are the most common method used. The latter should be repeated at frequent intervals during the high seasons to manage the long life span of the sand flies; however, this is neither economically nor environmentally sound. In addition to complications resulted from the development of insecticide resistance. The present study investigated the first steps of an alternative approach, one whereby the plant communities in areas with high populations of sand flies could be cultivated to favor species whose presence would naturally decrease the sand fly population. Plants are rich sources of complex, yet unexplored mixtures of bioactive phytochemicals that can be further exploited to act as vector control measure tools. We and others, Schlein and Jacobson (1999) have shown that although $R$. communis and B. glabra are suitable sugar sources for $P$. papatasi, this feeding incurs a strong, deleterious effect on sand fly survival. The present experiments have further shown a significant effect on egg production, larval and pupal development and adult emergence. Although further studies are required to determine the precise impact of creating barrier zones with such plants ( $R$. communis and B. glabra), our results to date present a plausible, cost effective and sustainable alternative to insecticides. Consequently, it can be considered an important asset in all the Integrated Vector Control Management Programs aimed at reducing Leishmania infections by decreasing their vectors population.

Continued studies investigating the sand fly-plant relationship with special emphasis on the development of Leishmania spp. is highly needed for better understanding of effective natural tools that could be widely used in sand fly control measures and to decrease the risk of leishmaniasis in the endemic areas.

\section{Acknowledgements}

Authors would like to thank GEIS for funding sand fly colony, Dr. Shabaan ElHossary, Dr. Adel Ramzy and Ms. Noha Watany, Research and Training Centers on Vectors of Diseases (RTC), and Department of Entomology of Ain Shams University for their technical support during the course of this work. Special thanks for the U.S. Naval Medical Research Unit No.3, Cairo, and Botany Department of Ain Shams University for hosting the research work conducted herein. Also, thanks are due to Dr. Joseph W. Diclaro II for constructive edits.

Financial support: Global Emerging Infections System (GEIS), GEIS-Baseline Project \# 10333_12_N3

Disclaimer: The views expressed in this article are those of the authors and do not necessarily reflect the official policy or position of the Department of the Navy, Department of Defense, nor the U.S. Government. The first author is an employee of the U.S. Government. This work was prepared as part of my official duties. Title 17 U.S.C. $\$ 105$ provides that 'Copyright protection under this title is not available for any work of the United States Government'. Title 17 U.S.C. $\$ 101$ defines a U.S. Government work as a work prepared by a military service member or employee of the U.S. Government as part of that person's official duties. *The experiments reported herein were conducted in compliance with the Animal Welfare Act and in accordance with the principles set forth in the "Guide for the Care and Use of Laboratory Animals", Institute of Laboratory Animals Resources, National Research Council, National Academy Press, 1996, and under NAMRU-3 Animal protocol No. 11-02.

\section{References}

Alborzi, A, Rasouli, M, Shamsizadeh, A, 2006: Leishmania tropica-isolated patient with 
visceral leishmaniasis in southern Iran. Am. J. Trop. Med. Hyg. 74:306-7.

Amóra, S, Bevilaqua, C, Feịjó, F, Alves, N, Maciel, M, 2009: Control of phlebotomine (Diptera: Psychodidae) leishmaniasis vectors. Neotrop. Entomol. 38:303-10.

Andrade-Coelho, C, Souza, N, Gouveia, C, Silva, V, Gonzalez, M, et al, 2009: Effect of fruit and leaves of Meliaceae plants (Azadirachta indica and Melia azedarach) on the development of Lu. longipalpis larvae (Diptera: Psychodidae: Phlebotominae) under experimental conditions. J. Med. Entomol. 46:1125-30.

Aouinty, B, Oufara, S, Mellouki, F, Mahari, S, 2006: Evaluation préliminaire de l'activité larvicide des extraits aqueux des feuilles du ricin (Ricinus communis L.) et $\mathrm{du}$ bois de thuye (Tetraclinis articulata (Vahl) Mast.) sur les larves de quatre moustiques culicidés: Culex pipiens (Linné), Aedes caspius (Pallas), Culiseta longiareolata (Atiken) et Anopheles maculipennis (Meigen). Biotechnol. Agron. Soc. Environ. 10:67-71.

Benkova, I, Volf, P, 2007: Effect of temperature on metabolism of Phlebotomus papatasi (Diptera: Psychodidae). J. Med. Entomol. 44:150-4.

Feliciangeli, M, 2004: Natural breeding places of phlebotomine sandflies. Med. Vet. Entomol. 18:71-80.

Ghosh, S, Tiwari, S, Srivastava, S, Sharma, A, Kumar, S, et al, 2013: Acaricidal properties of Ricinus communis leaf extracts against organophosphate and pyrethroids resistant Rhipicephalus (Boophilus) microplus. Vet. Parasitol. 192:259-67.

Hoel, D, Butler, J, Fawaz, E, Watany, N, ElHossary, S, et al, 2007: Response of phlebotomine sand flies to light-emitting diodemodified light traps in Southern Egypt. J. Vector Ecol. 32:302-8.

Jacobson, R, Schlein, Y, 1999: Lectins and toxins in the plant diet of Phlebotomus papatasi (Diptera: Psychodidae) can kill Leishmania major promastigotes in the sandfly and in culture. Ann. Trop. Med. Parasitol. 93:351-6.

Janson, E, Stireman III, J, Singer, M, Abbot, P, 2008: Phytophagous insect-microbe mutual- lism and adaptive evolutionary diversification. Evolution, 62:997-1012.

Joshny, J, Devi, R, Hari, V, 2012: Phytochemical and in-vitro anthelmintic activity of hydro alcoholic extract of Bougainvillea glabra. Int. J. Pharm. Pharm. Sci. 4:115-7.

Killick-Kendrick, R, 1999: The biology and control of phlebotomine sand flies. Clin. Dermatol. 17:279-89.

Kumar, S, Wahab, N, Mishra, M, Warikoo, R, 2012: Evaluation of 15 local plant species as larvicidal agents against an Indian strain of dengue fever mosquito, Aedes aegypti L. (Diptera: Culicidae). Front. Physiol. 104:1-6.

Levin, H, Friedman, H, Palevitch, D, Perl, M, 1988: Partial purification and some properties of an antibacterial compound from Aloe vera. Phytother. Res. 2: 67-69.

Luitgards-Moura, J, Castellon Bermudez, E, Rocha, A, Tsouris, P, Rosa-Freitas, M, 2002: Preliminary assays indicate that Antonia ovata (Loganiaceae) and Derris amazonica (Papilionaceae), ichthyotoxic plants used for fishing in Roraima, Brazil, have an insecticide effect on Lutzomyia longipalpis (Diptera: Psychodidae: Phlebotominae). Mem. Inst. Oswaldo Cruz, 97: 737-42.

Modi, G, Tesh, R, 1983: A simple technique for mass rearing Lutzomyia longipalpis and Phlebotomus papatasi (Diptera: Psychodidae) in the laboratory. J. Med. Entomol. 20:568-9.

Moran, N, Tran, P, Gerardo, N, 2005: Symbiosis and insect diversification: an ancient symbiont of sap-feeding insects from the bacterial phylum Bacteroidetes. Appl. Environ. Microbiol. 71:8802-10.

Noguera, P, Rondón, M, Nieves, E, 2006: Effect of blood source on the survival and fecundity of the sandfly Lutzomyia ovallesi Ortiz (Diptera: Psychodidae), vector of Leishmania. Biomedica, 26:57-63.

Peterson, A, Shaw, J, 2003: Lutzomyia vectors for cutaneous leishmaniasis in sou-thern Brazil: ecological niche models, predicted geographic distributions, and climate change effects. Int. J. Parasitol. 33:919-31.

Porrozzi, R, Teva, A, Amaral, V, Santos da Costa, M, Grimaldi, G, 2004: Cross-immunity experiments between different species or strains 
of Leishmania in Rhesus Macaques (Macacamulatta). Am. J. Trop. Med. Hyg. 71:297-305.

Rondon, F, Bevilaqua, C, Accioly, M, Morais, S, Andrade-Junior, H, et al, 2011: In vitro effect of Aloe vera, Coriandrum sativum and Ricinus communis fractions on Leishmania infantum and on murine mono-cytic cells. Vet. Parasitol. 178:235-40.

Schlein, Y, Jacobson, R, 1994: Mortality of Leishmania major in Phlebotomus papatasi caused by plant feeding of the sand flies. Am. J. Trop. Med. Hyg. 50:20-7.

Schlein, Y, Jacobson, R, 1999: Sugar meals and longevity of the sandfly Phlebotomus papatasi in an arid focus of Leishmania major in the Jordan Valley. Med. Vet. Entomol. 13: 6571.

Schlein, Y, Jacobson, R, 2008: High nocturnal $\mathrm{CO}_{2}$ emanation guides the sand fly Phlebotomus papatasi to sugar-rich plants. Physiol. Entomol. 33:353-9.

Schlein, Y, Jacobson, R, Muller, G, 2001: Sandfly feeding on noxious plants: A potential method for the control of leishmaniasis. Am. J. Trop. Med. Hyg. 65:300-3.

Schlein, Y, Yuval, B, 1987: Leishmaniasis in the Jordan Valley. IV. Attraction of Phlebo- tomus papatasi (Diptera: Psychodidae) to plants in the field. J. Med. Entomol. 24:87-90.

Sen, G, Mukhopadhyay, S, Ray, M, Biswas, T, 2008: Quercetin interferes with iron metabolism in Leishmania donovani and ribonucleotide reductase to exert leishmanicidal activity. J. Antimicrob. Chemother. 1:1-10.

Srinivasan, R, Kalyanasundaram, M, 2001: Relative efficacy of DEPA and neem oil for repellent activity against Phlebotomus papatasi, the vector of leishmaniasis. J. Commun. Dis. 33:180-4.

Su-Xia, X, Chun-Song, L, Qing-Yun, H, Li, L, $\mathrm{Bi}-\mathrm{Yu}, \mathrm{Z}, 2010$ : Analysis and comparison of flavonoids in three Bougainvilleas by micellar electrokinetic chromatography. Bull. Botanical Res. 30:718-24.

Valerio, L, Maroli, M, 2005: Valutazione dell'effetto repellente ed anti-feeding dello'oliod'aglio (Allium sativum) nei confronti dei flebotomi (Diptera: Psychodidae). Ann. Ist. Super Sanita 41: 253-6.

Willcocks, F, 1917: Notes on some insects found in Egypt of medical and veterinary interest. Bull. Soc. Ent. d'Egypt 10:79.

\section{Legends for figures}

Fig. 1: A blood-fed female P. papatasi showing blue-dyed gut indicating plant meal uptake Fig. 2: Number of fed and fed-dead Phlebotomus papatasi after feeding on Ricinus communis Fig. 3: Number of fed and fed-dead Phlebotomus papatasi after feeding on Bougainvillea glabra

Fig. 4: Number of fed and fed-dead Phlebotomus papatasi after feeding on $30 \%$ sucrose solution 


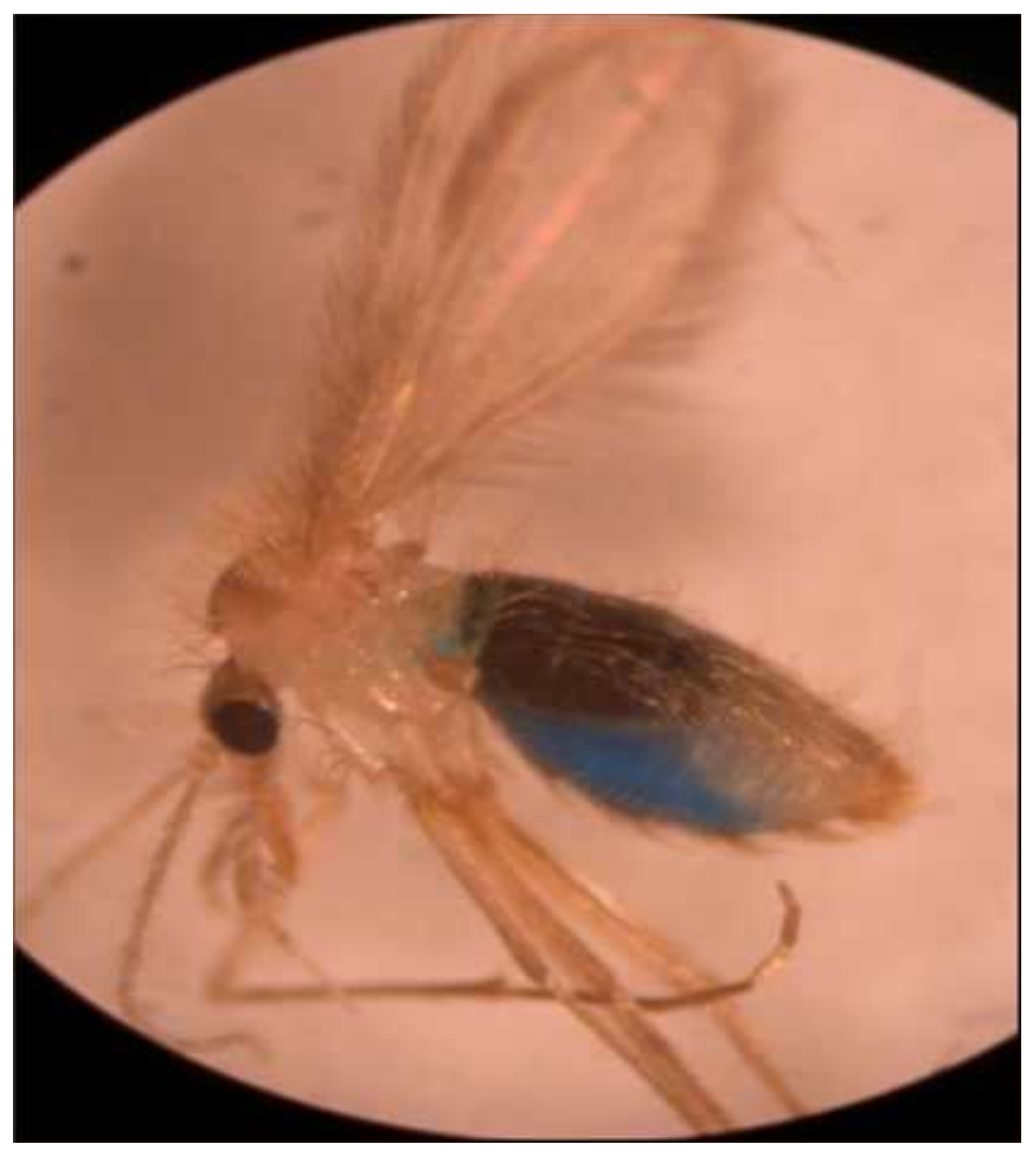

Fig. 1: A blood-fed female Phlebotomus papatasi showing blue-dyed gut indicating plant meal uptake

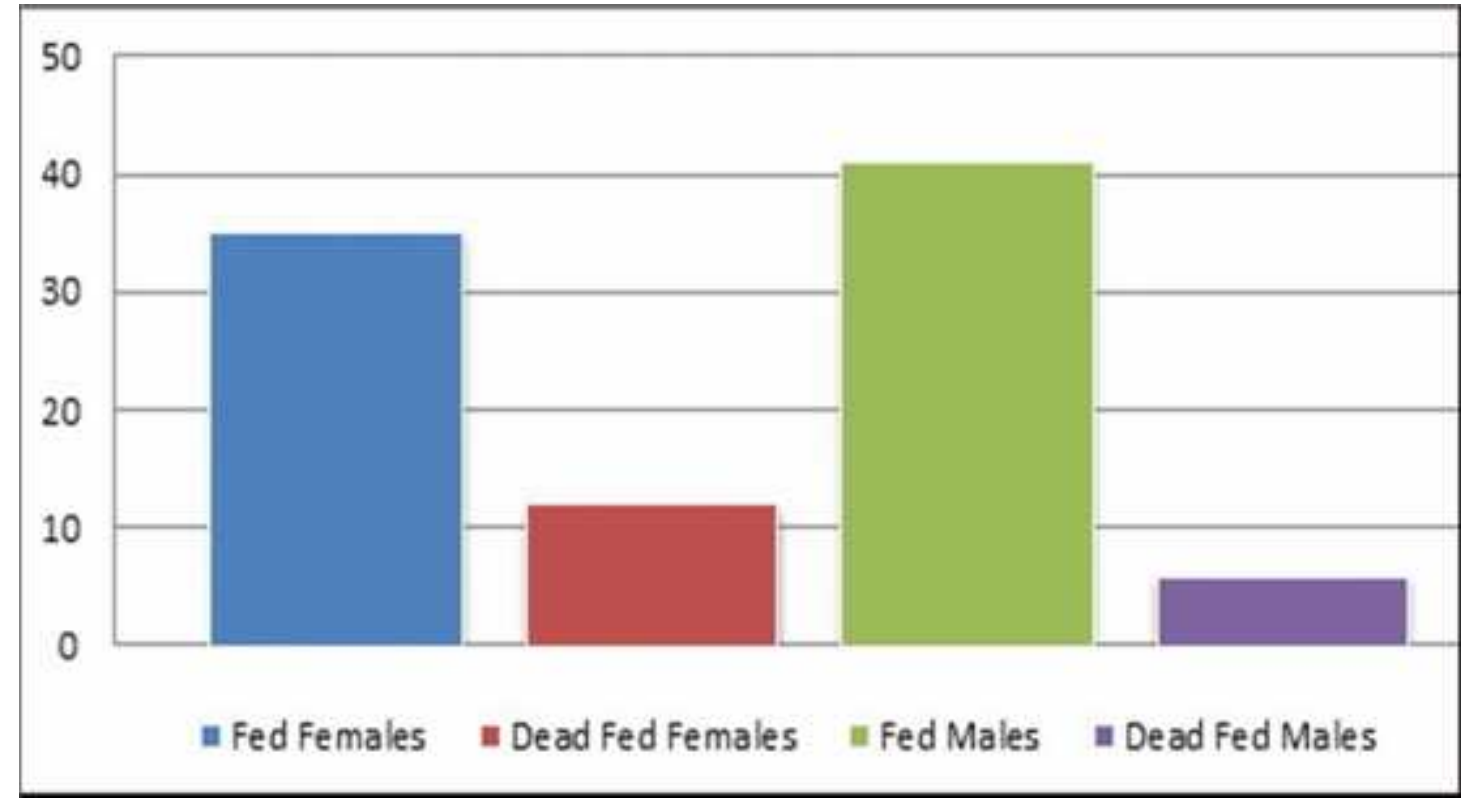

Fig. 2: Number of fed and fed-dead Phlebotomus papatasi after feeding on Ricinus communis 


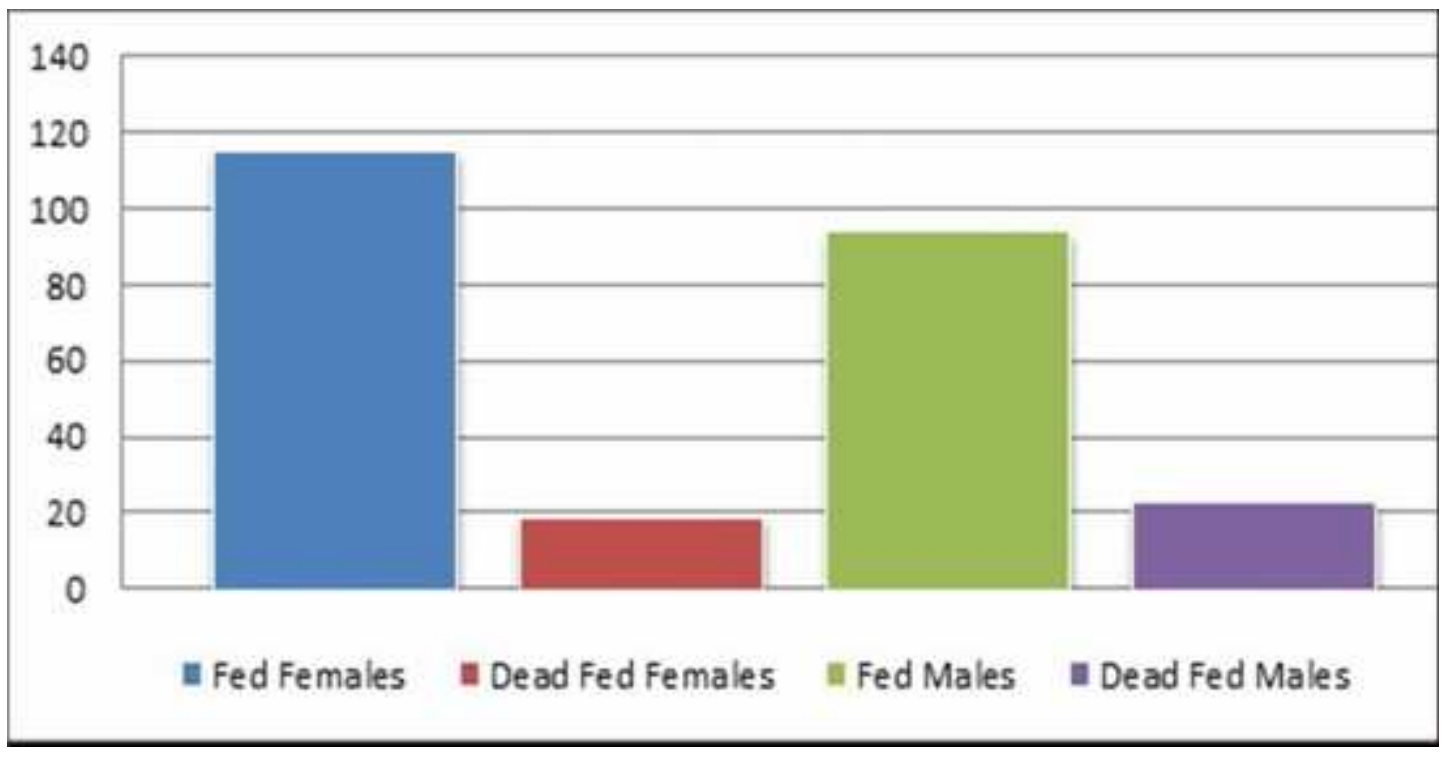

Fig. 3: Number of fed and fed-dead Phlebotomus papatasi after feeding on Bougainvillea glabra

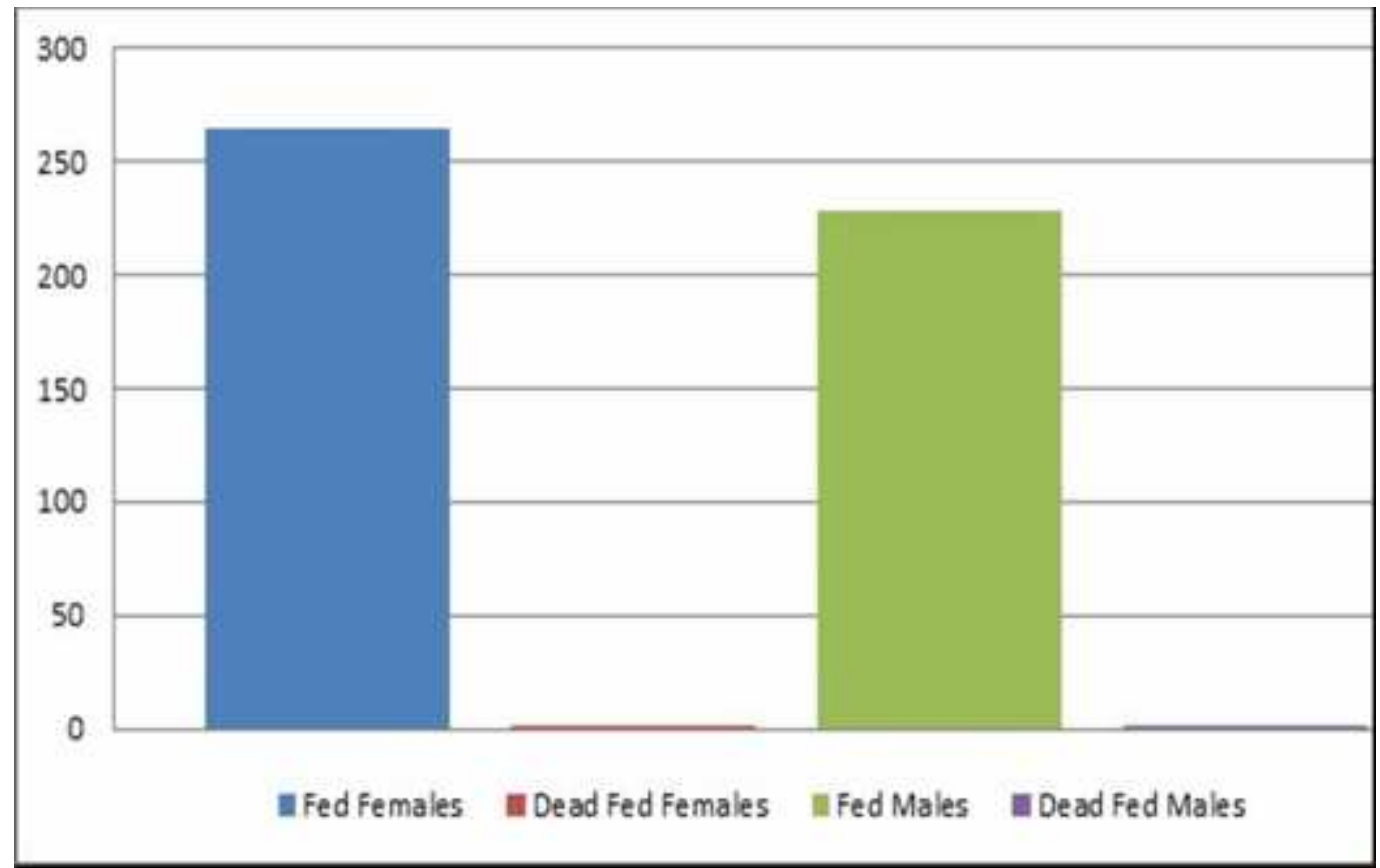

Fig. 4: Number of fed and fed-dead Phlebotomus papatasi after feeding on $30 \%$ sucrose solution 